\title{
Decadal variability of the upper ocean heat content in the East/Japan Sea and its possible relationship to northwestern Pacific variability
}

\author{
Hanna Na, ${ }^{1}$ Kwang-Yul Kim, ${ }^{1}$ Kyung-Il Chang, ${ }^{1}$ Jong Jin Park, ${ }^{2}$ Kuh Kim, ${ }^{3}$ \\ and Shoshiro Minobe ${ }^{4}$ \\ Received 9 June 2011; revised 7 December 2011; accepted 7 December 2011; published 9 February 2012.
}

[1] The upper ocean heat content variability in the East/Japan Sea was investigated using a 40 year temperature and salinity data set from 1968 to 2007 . Decadal variability was identified as the dominant mode of variability in the upper ocean $(0-300 \mathrm{~m})$ aside from the seasonal cycle. The decadal variability is strong to the west of northern Honshu, west of the Tsugaru Strait, and west of southern Hokkaido. Temperature anomalies at 50-125 m exhibit a large contribution to the decadal variability, particularly in the eastern part of the East/Japan Sea. The vertical structure of regressed temperature anomalies and the spatial patterns of regressed $10^{\circ} \mathrm{C}$ isotherms in the East/Japan Sea suggest that the decadal variability is related to upper ocean circulation in the East/Japan Sea. The decadal variability also exhibits an increasing trend, which indicates that the regions showing large decadal variations experienced warming on decadal time scales. Further analysis shows that the decadal variability in the East/Japan Sea is not locally isolated but is related to variability in the northwestern Pacific.

Citation: Na, H., K.-Y. Kim, K.-I. Chang, J. J. Park, K. Kim, and S. Minobe (2012), Decadal variability of the upper ocean heat content in the East/Japan Sea and its possible relationship to northwestern Pacific variability, J. Geophys. Res., 117, C02017, doi:10.1029/2011JC007369.

\section{Introduction}

[2] The ocean, which has the highest heat capacity in the climate system, has experienced significant change in global heat content over the past 40 years [Levitus et al., 2000]. To understand the ocean's role in the climate system, the global ocean's ability to store and transport heat has been extensively studied by a number of researchers, who have mostly focused on upper ocean warming [Levitus et al., 2000, 2005, 2009; Gouretski and Koltermann, 2007; Domingues et al., 2008] in association with the ocean's significant contribution to global warming and climate change [Houghton et al., 1996]. While the globally averaged upper ocean heat content in recent years shows an increasing trend in nearly a linear fashion [Willis et al., 2004; Lyman et al., 2010], the upper ocean heat content averaged over the regional oceans exhibits large decadal variations rather than a steady warming [Levitus et al., 2000; Willis et al., 2004; Palmer et al., 2009]. Moreover, spatial patterns of heat content change indicate that warming is not uniform over space [Lozier et al., 2008; Palmer et al., 2009]. Thus, the warming signals and decadal

\footnotetext{
${ }^{1}$ School of Earth and Environmental Sciences, Seoul National University, Seoul, South Korea.

${ }^{2}$ Department of Physical Oceanography, Woods Hole Oceanographic Institution, Woods Hole, Massachusetts, USA.

${ }^{3}$ Research Institute of Oceanography, Seoul National University, Seoul, South Korea.

${ }^{4}$ Graduate School of Science, Hokkaido University, Sapporo, Japan.

Copyright 2012 by the American Geophysical Union. 0148-0227/12/2011JC007369
}

variability in the marginal seas need to be investigated from a regional point of view and to be compared with those in the larger ocean basins.

[3] The East/Japan Sea (the EJS hereafter) is a semienclosed marginal sea in the northwestern Pacific (Figure 1). While its dynamics, such as bottom water formation and deep circulation, are to a large extent separated from the neighboring seas [Kim et al., 2004], it is connected with the neighboring seas through straits [Cho et al., 2009; Na et al., 2009]. The maximum sill depth of the straits is shallower than $300 \mathrm{~m}$; the maximum depth of the basins in the EJS, on the other hand, is deeper than $3000 \mathrm{~m}$ (Figure 1). Hirose et al. [1996], Isoda [1999], and Han and Kang [2003] showed that the heat supply by the warm inflow through the Korea Strait, the Tsushima Warm Current, is balanced by a significant surface heat loss in the EJS. The upper ocean circulation and hydrography in the EJS is also highly affected by the Tsushima Warm Current [Chang et al., 2004; Yoon and Kim, 2009]. Considering that the Tsushima Warm Current originates in the northwestern Pacific, heat content variability in the northwestern Pacific could affect the upper ocean circulation and hydrography of the EJS.

[4] A connection between the EJS and the northwestern Pacific was reported by Gordon and Giulivi [2004]; the lowfrequency variability of sea surface height (SSH) in the EJS is associated with the Pacific Decadal Oscillation (PDO). They reported that the decadal variability in the EJS is in phase with the PDO; a higher SSH, warmer temperature, and lower salinity in the surface layer were observed during the negative phase of the PDO, with opposite trends observed during the positive PDO phase. The authors also suggested 


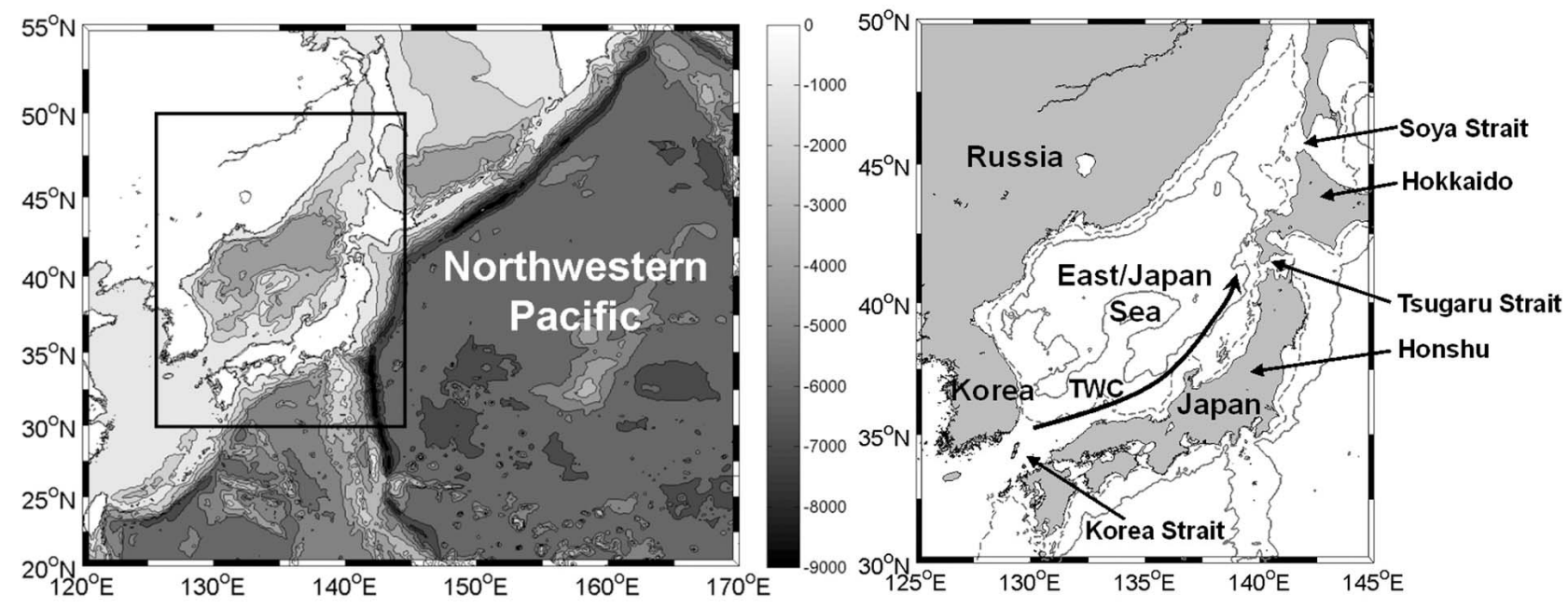

Figure 1. Geographic map of (left) the northwestern Pacific and (right) the East/Japan Sea. Figure 1 (right) is an enlargement of the area in the solid box in Figure 1(left) with $3000 \mathrm{~m}$ (gray solid line) and $300 \mathrm{~m}$ (gray dotted line) isobaths. A schematic path of the Tsushima Warm Current (TWC) is depicted in Figure 1(right).

that changes in the geostrophic transport of the Kuroshio Current appear to account for the variability of SSH in the EJS-PDO relationship. The transport of the Kuroshio is out of phase with that of the Tsushima Warm Current; as the Kuroshio weakens, the inflow of subtropical North Pacific water through the Korea Strait could increase because the weak Kuroshio could induce a decreased pressure gradient between the subtropical North Pacific and the EJS [Gordon and Giulivi, 2004, Figure 7]. The opposite case would occur as the Kuroshio Current strengthened.

[5] In this study, the upper ocean heat content variability in the EJS is investigated from a regional point of view and is compared with northwestern Pacific variability. The upper ocean heat content in the EJS is derived using a 40 year observational data set from 1968 to 2007 . The data and the description of the analytical tools used in this study are described in section 2 . The decadal variability in heat content, along with its increasing trend, is examined, and its relationship with the upper ocean temperature variability in the EJS is investigated in sections 3 and 4. A comparison with heat content variability in the northwestern Pacific follows in section 5, and the possible causes of decadal variability in the EJS are discussed in section 6.

\section{Data and Methods}

\subsection{Data}

[6] The monthly mean temperature and salinity data set from the EJS has a spatial resolution of $0.5^{\circ}$ with 18 levels in the upper $1000 \mathrm{~m}(0,10,20,30,50,75,100,125,150,200$, $250,300,400,500,600,700,800$, and $1000 \mathrm{~m})$. The gridded data set was produced using the ocean observation profiles archived in the World Ocean Database 2005 [Boyer et al., 2006], which includes various data sets, such as high-resolution conductivity-temperature-depth (CTD) data, moored buoy data, profiling float data, and drifting buoy data, among others. The observation densities are large in the southeastern EJS and small in the northwestern EJS [Minobe et al., 2004, section 3]. Before gridding, a quality control was conducted by removing data points with an anomaly from the climatological mean at each grid point greater than 3 standard deviations in magnitude. The data were temporally and spatially smoothed using the same optimal interpolation scheme as used by Minobe et al. [2004] and Na et al. [2010]. The new data set has more vertical levels, as described above, and is updated until 2007. The data from 1968 until 2007, a total of 480 months, were used for this study.

[7] After gridding, minor interpolation is necessary due to the low number of observations. Every missing value at each time step is assigned the mean value of the surrounding 4 grid points at the same level, if they are all available. If the number of consecutive missing values is not greater than a time gap of 4 months, the missing values are interpolated using a cubic spline method; no extrapolation is applied. Finally, if observations are available for more than $90 \%$ of the data period at each grid point and if the number of consecutive missing values is not greater than a time gap of 12 months, the missing values are replaced by the respective monthly climatological mean.

[8] In the northwestern Pacific, the temperature and salinity data are taken from the Simple Ocean Data Assimilation Reanalysis (SODA) data set [Carton and Giese, 2008] for the time period of 1968 to 2007, instead of generating a gridded data set from the World Ocean Database. Though the SODA data set may not well represent the temperature structure in the EJS, primarily because of the smaller spatial scales of vertical and horizontal variability in the EJS compared to those in the open ocean [Park and Kim, 2007, Figure 1], it performs fair enough to investigate the temperature variability in the North Pacific [Zheng and Giese, 2009; Kang et al., 2010]. The monthly mean SODA data set with a spatial resolution of $0.5^{\circ}$ is used to calculate the upper ocean heat content in the northwestern Pacific and to discuss the connectivity between the EJS and the northwestern Pacific in terms of heat content variability.

\subsection{Calculation of Heat Content}

[9] The upper 12 levels from $0 \mathrm{~m}$ to $300 \mathrm{~m}$ are selected for the calculation of the heat content in the EJS because of the 
lack of observational data below $300 \mathrm{~m}$ even after the interpolation. If less than 2 of the vertical levels of temperature and salinity are missing, the 12 levels of data are linearly interpolated at every $1 \mathrm{~m}$ in depth; no extrapolation is conducted if the top or bottom data are missing. The vertically integrated heat content, $Q$, is then calculated using the following equation:

$$
Q=\int_{-300}^{0} \rho(T, S, 0) c_{p}(T, S, 0) T(z) d z,
$$

where $T$ is temperature, $S$ is salinity, $\rho$ is density and $c_{p}$ is the specific heat capacity at constant pressure.

[10] The heat content, $Q$, was calculated only for grid points where interpolated temperature profiles are available for the entire data period, from 1968 to 2007. As a result, the upper $300 \mathrm{~m}$ integrated heat content does not cover the northwestern region of the EJS, where the data density is relatively low. Whenever the temperature profile is available while the salinity profile is not, the monthly climatological mean salinity is used for the calculation of heat content because the number of missing salinity values exceeds the number of missing temperature values. The heat content change is minimal with and without this replacement by climatological salinity, as heat content variability is dominated by temperature variability rather than by salinity variability, particularly in the upper ocean (data not shown here).

[11] The temperature and salinity data from the SODA data set have 17 vertical layers in the upper approximately $300 \mathrm{~m}$. The mean depths of the vertical layers are from $5.01 \mathrm{~m}$ to $317.65 \mathrm{~m}$. The upper $300 \mathrm{~m}$ integrated heat content in the northwestern Pacific is calculated as in equation (1) after a linear interpolation at every $1 \mathrm{~m}$ depth interval.

\subsection{Cyclostationary EOF Analysis}

[12] A cyclostationary empirical orthogonal function (CSEOF) analysis [Kim et al., 1996; Kim and North, 1997] is applied to the upper ocean heat content in the EJS. The CSEOF technique is useful for extracting physically evolving spatial patterns. Space-time data, $Q(r, t)$, are decomposed into cyclostationary loading vectors (CSLVs), $\operatorname{CSLV}_{n}(r, t)$, and their corresponding principal component (PC) time series, $P C_{n}(t)$, as shown in (2):

$$
Q(r, t)=\sum_{n} \operatorname{CSLV}_{n}(r, t) P C_{n}(t),
$$

where $n, r$, and $t$ denote the mode number, space and time, respectively. Each CSLV represents a physical evolution, and the corresponding PC time series shows the temporally varying strength of the physical evolution. The CSLVs are periodic with a nested period, $d$, which is set to be 12 months in this study:

$$
\operatorname{CSLV}_{n}(r, t)=\operatorname{CSLV}_{n}(r, t+d) .
$$

[13] Note that the CSLVs are orthogonal to each other in space and time (nested period), and the PC time series are mutually uncorrelated. The physical evolution within the nested period is captured in the resulting spatial patterns after the CSEOF analysis. The long-term evolution of the physical process is reflected in the corresponding PC time series.
[14] A regression analysis between a target variable and a predictor variable allows us to understand the physical relationship between them. After a predictor variable is decomposed into CSLVs, their PC time series are regressed onto the PC time series of the target variable, as shown in (4):

$$
P C_{i}^{(T)}(t)=\sum_{n=1}^{N} a_{n} P C_{n}^{(P)}(t)+\varepsilon(t),
$$

where $P C_{i}^{(T)}(t)$ is the target PC time series for mode $i, P C_{n}^{(P)}(t)$ is the predictor time series for mode $n, a_{n}$ is the regression coefficient for mode $n$, and $\varepsilon(t)$ is the regression error. In this study, fifteen predictor time series are used for the regressions $(N=15)$. Then, the regression patterns of the predictor variable, $\operatorname{CSL} V_{i}^{(P R)}(r, t)$, are obtained using the regression coefficients, as shown in (5):

$$
\operatorname{CSLV}_{i}^{(P R)}(r, t)=\sum_{n=1}^{N} a_{n} \operatorname{CSLV}_{n}^{(P)}(r, t),
$$

where $\operatorname{CSL}_{n}^{(P)}(r, t)$ are the CSLVs of the predictor variable. The resulting spatial patterns represent the evolution of the predictor variable, which is physically consistent with the evolution of the target variable.

[15] The main motivations for applying the CSEOF technique in this study are to extract the independent modes of upper ocean heat content variability in the EJS and to investigate their characteristics. Once the CSEOF technique is applied to the upper ocean heat content data in the EJS, a target mode is selected (the decadal mode in this study). After CSEOF analysis is also conducted on the predictor variables (the upper ocean temperature at each depth, the depth of the $10^{\circ} \mathrm{C}$ isotherms and the upper ocean heat content variability in the northwestern Pacific), the regressed patterns of the predictor variables are obtained as in (4) and (5). The relationship between the target mode and predictor variables is investigated by comparing the spatial patterns of the target mode and the regressed anomalies of the predictor variables.

\section{Upper Ocean Heat Content Variability in the East/Japan Sea}

[16] Figures $2 \mathrm{a}$ and $2 \mathrm{~b}$ show the mean and the standard deviation of the upper $300 \mathrm{~m}$ heat content in the EJS from 1968 to 2007 . The means and standard deviations are relatively large in the southern part of the EJS and along the west coast of Japan, while they are relatively small in the northwestern part of the EJS. A strong meridional gradient exists along approximately $40^{\circ} \mathrm{N}$, which is the latitude of the Subpolar Front [Park et al., 2007]. The mean upper ocean heat content in Figure 2a displays a similar spatial pattern to the mean temperature at $100 \mathrm{~m}$ (data not shown); the pattern correlation between them is approximately 0.99 .

[17] The linear trend from 1968 to 2007 in the upper ocean heat content is presented in Figure 2c. The figure shows a spatially inhomogeneous trend of heat content changes during the 40 years, based on linear least square fitting. A conspicuous positive trend is observed in the eastern EJS, while there is no significant positive or negative trend in the western EJS. Thus, the warming trend in the EJS does not 

(a) MEAN $\left({ }^{*} 10^{6} \mathrm{~J} / \mathrm{m}^{2}\right)$
(b) STANDARD DEVIATION $\left({ }^{*} 10^{6} \mathrm{~J} / \mathrm{m}^{2}\right)$
(c) TREND $\left({ }^{*} 10^{6} \mathrm{~J} / \mathrm{m}^{2}\right)$
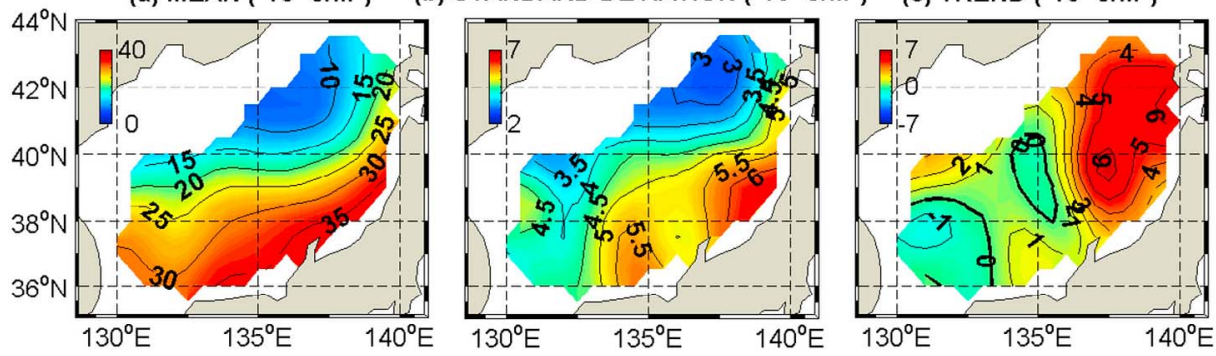

Figure 2. (a) Mean, (b) standard deviation, and (c) linear trend over 40 years of the upper $300 \mathrm{~m}$ heat content in the East/Japan Sea. The contour intervals in Figures $2 \mathrm{a}, 2 \mathrm{~b}$, and $2 \mathrm{c}$ are 0.5, 0.5, and 1.0, respectively. The bold solid lines in Figure 2c represent the zero contours.
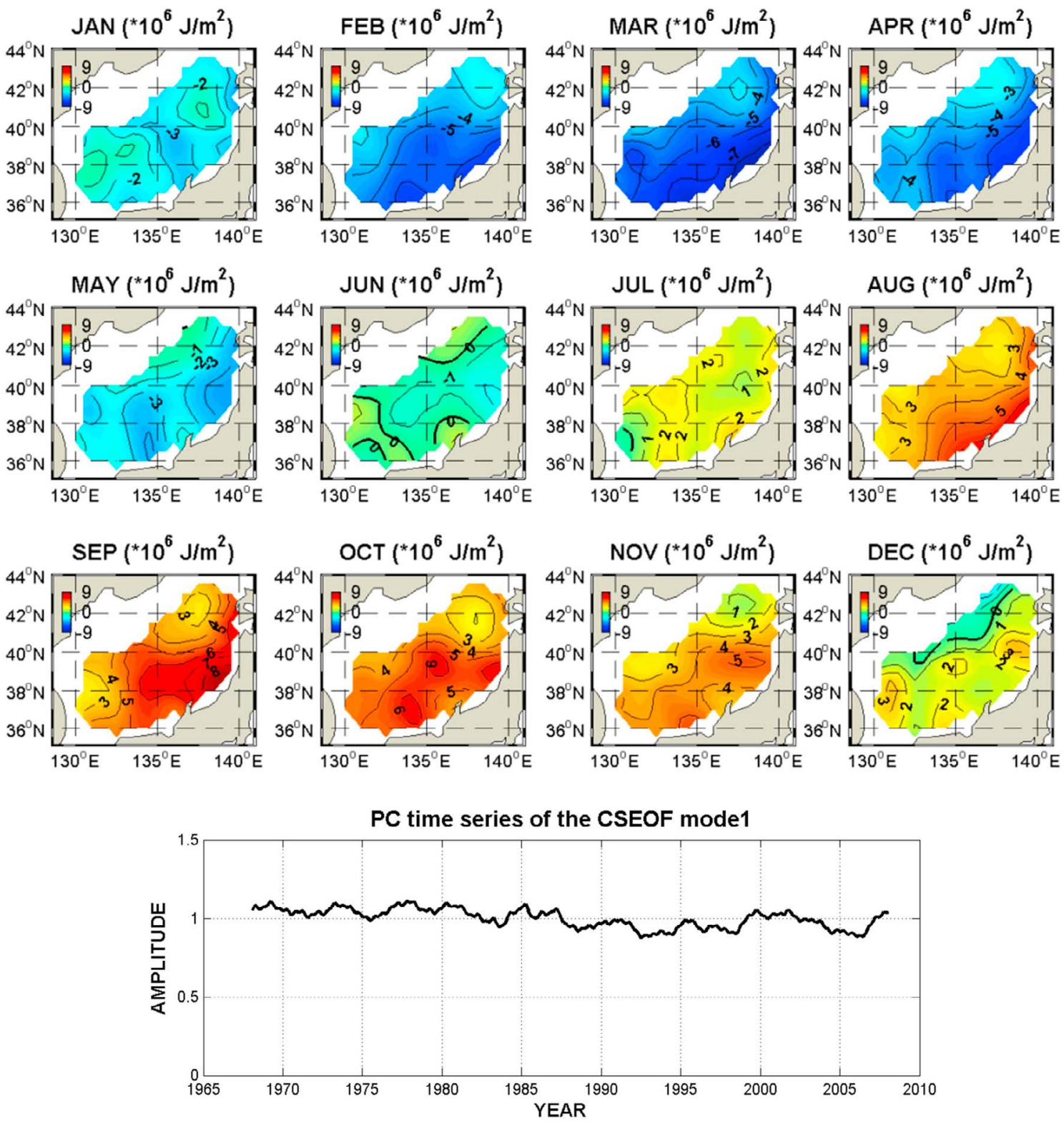

Figure 3. The first CSEOF mode and the corresponding PC time series of the upper ocean heat content $\left(\times 10^{6} \mathrm{~J} / \mathrm{m}^{2}\right)$ in the East/Japan Sea. The contour interval is 1.0 , and the bold solid lines in the spatial patterns represent the zero contours. The strength of the physical evolution depicted in the spatial patterns varies from 1968 to 2007, according to the PC time series. This mode represents the seasonal cycle. 

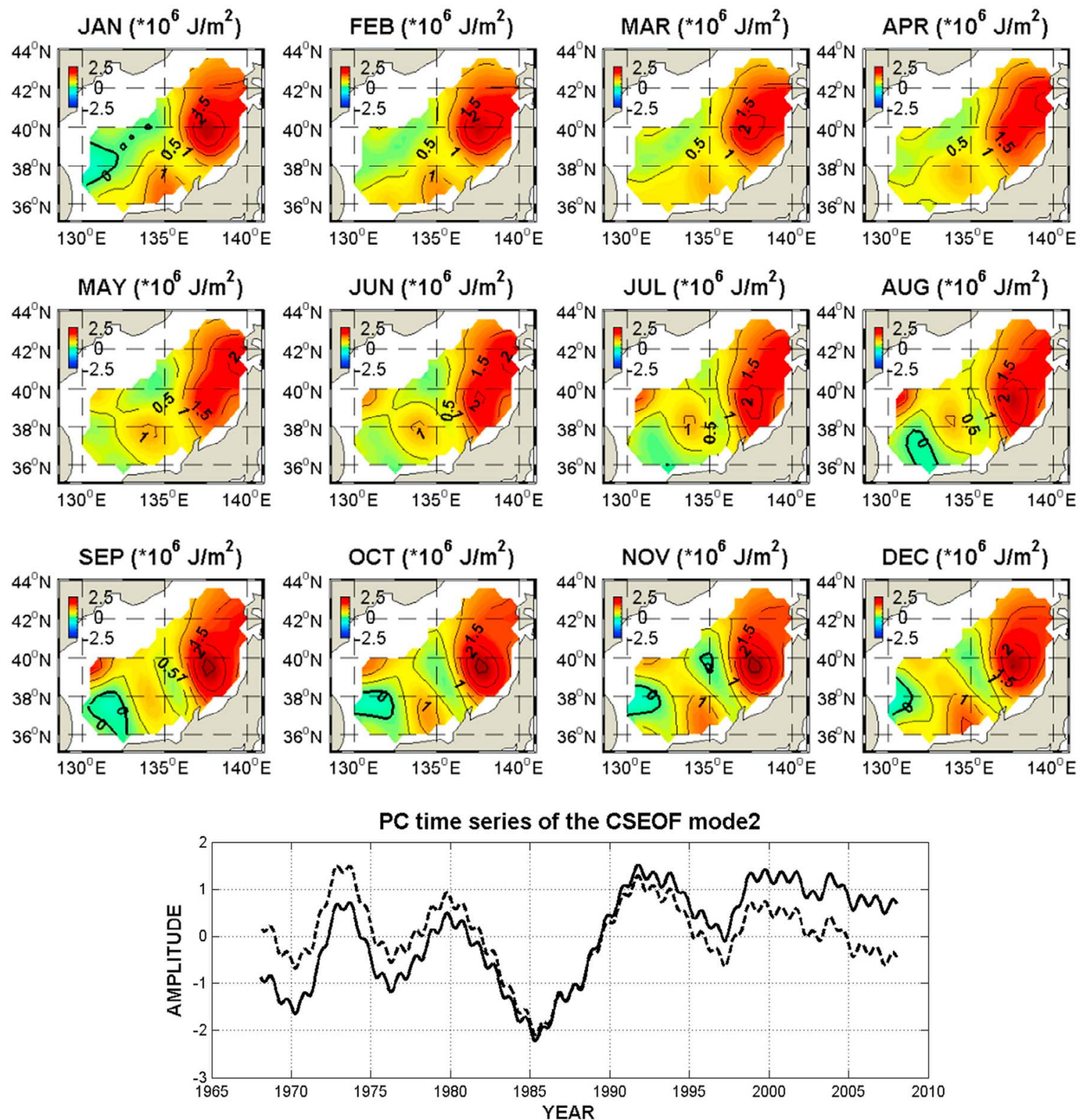

Figure 4. The second CSEOF mode and the corresponding PC time series of the upper ocean heat content $\left(\times 10^{6} \mathrm{~J} / \mathrm{m}^{2}\right)$ in the East $/ \mathrm{Japan}$ Sea. The contour interval is 0.5 , and the bold solid lines in the spatial patterns represent the zero contours. The solid and dashed lines in the bottom panel represent the original PC time series and the detrended PC time series, respectively. This mode represents the decadal variability in the upper ocean heat content.

appear to be a simple process, such as the result of an inflow of warmer water filling the entire basin, but instead appears to be related to the upper ocean circulation variability in the EJS. Moreover, the time series of upper ocean heat content at each grid point in the eastern EJS does not show a linearly increasing trend from 1968 to 2007. A detailed analysis of the warming signal and decadal variability in the upper ocean heat content is described in the present section.

[18] Figure 3 shows the first CSEOF mode and the corresponding PC time series, which explains $83 \%$ of the total variance of the upper ocean heat content in the EJS. The first mode is the seasonal cycle, with positive anomalies during summer and fall and negative anomalies during winter and spring. The large variance along the west coast of Japan suggests that the variation of the Tsushima Warm Current is an important component of the seasonal cycle. The timing of a maximum heat content anomaly in September-October and a minimum in February-March is consistent with seasonal variations in the mass transport of the Tsushima Warm Current [Takikawa et al., 2005; Na et al., 2009], supporting the idea that variation in the Tsushima Warm Current drives the seasonal cycle of heat content in the EJS.

[19] The second CSEOF mode in Figure 4 explains approximately $7 \%$ of the total variance; it is equivalent to approximately $41 \%$ of the variability, aside from the variability due to the seasonal cycle. The spatial patterns in 
(a) $0 \mathrm{~m}$

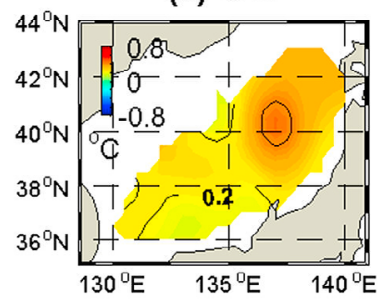

(e) $50 \mathrm{~m}$

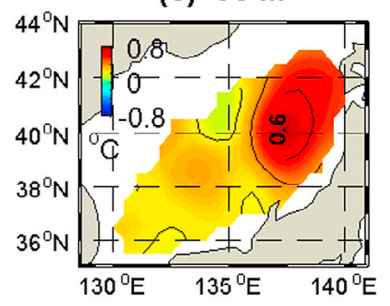

(i) $150 \mathrm{~m}$

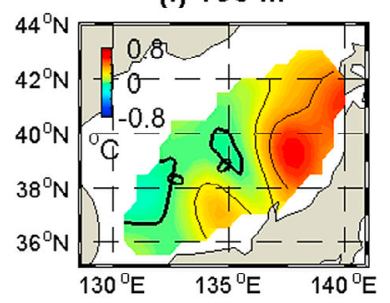

(b) $10 \mathrm{~m}$

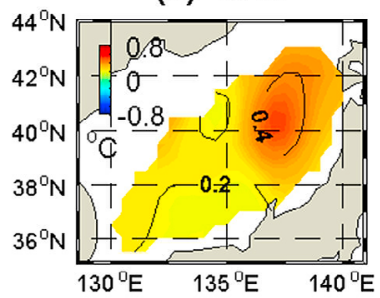

(f) $75 \mathrm{~m}$

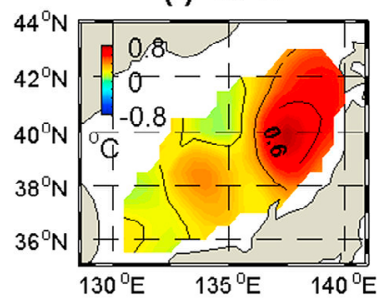

(j) $200 \mathrm{~m}$

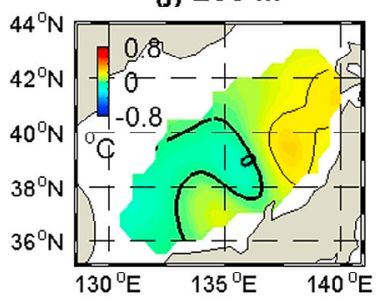

(c) $20 \mathrm{~m}$

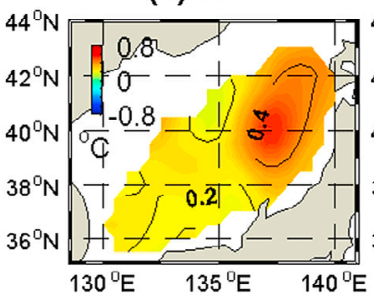

(g) $100 \mathrm{~m}$

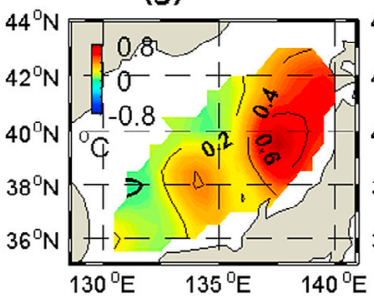

(k) $250 \mathrm{~m}$

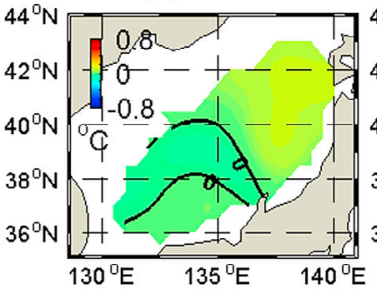

(d) $30 \mathrm{~m}$

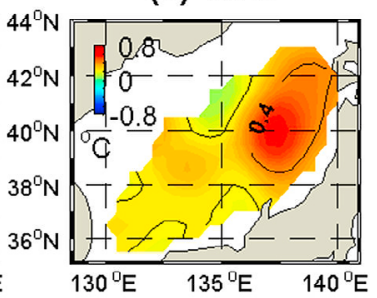

(h) $125 \mathrm{~m}$

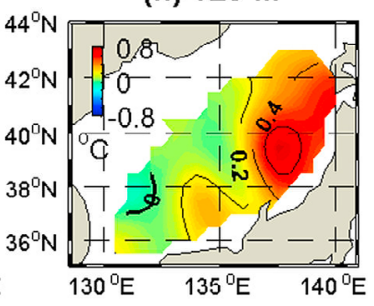

Figure 5. Temperature anomalies $\left({ }^{\circ} \mathrm{C}\right)$ at each vertical level regressed onto the decadal variability of the upper ocean heat content in the East/Japan Sea. The contour interval is 0.2, and the bold solid lines represent the zero contours. Each spatial pattern represents the 12 month average of the loading vectors.

Figure 4 show generally positive anomalies throughout the year. Particularly, there are large positive anomalies to the west of northern Honshu, at the western end of the Tsugaru Strait, and west of southern Hokkaido. The southwestern region, in contrast, shows small negative anomalies. The regions of positive anomalies in the eastern EJS are fairly consistent with those with a positive trend in Figure 2c.

[20] The PC time series in Figure 4 exhibits long-term fluctuations with a period of approximately 10 years and an increasing trend; the best autoregressive (AR) power spectral density function of order 24 of the detrended PC time series shows a statistically significant spectral peak at approximately 10 years. Thus, this mode represents decadal variability of the upper ocean heat content in the EJS. The PC time series also shows an increasing trend, which is approximately $25 \%$ of the decadal fluctuation range, although the trend is not very obvious in the midst of much stronger decadal variability. The spatial patterns show positive anomalies in general, indicating most regions in the EJS experienced a significant warming in the recent 20 years, according to the PC time series in Figure 4.

[21] Recent studies indicate that the globally averaged upper ocean heat content has steadily increased for 16 years, from 1993 to 2008 [e.g., Lyman et al., 2010]. It appears that the heat content in the EJS has neither significantly increased nor decreased for the recent 15 years from 1993 to 2007 as shown in Figure 4. Further, heat content change is not uniform in the EJS, and the warming signal, at first glance, seems to be a result of decadal variability. Consistency between the regions of positive trends in Figure $2 \mathrm{c}$ and those of positive anomalies in Figure 4 supports the hypothesis that the warming in the EJS is related to this decadal variability mode. The nature and the source of the decadal variability and warming is investigated in more detail in the context of the northwestern Pacific variability in section 5.

\section{Relationship Between Decadal Heat Content Variability and Upper Ocean Temperature in the East/Japan Sea}

[22] The CSEOFs of upper ocean temperature anomalies at each depth were regressed onto the decadal variability of heat content in Figure 4, as explained in section 2, and the resulting spatial patterns are shown in Figure 5. Because the upper ocean temperature at each depth was analyzed using the CSEOF technique with a nested period of 12 months, the same as the upper ocean heat content, the regressed temperature anomalies are obtained as 12 spatial patterns at each depth (see equations (4) and (5)). In Figure 5, the annually averaged loading vector, $C S L V_{i}^{(P R)}(r, t)$, is presented because the 12 spatial patterns of regressed temperature anomalies do not show a significant difference at each time step, similar to the target variable in Figure 4.

[23] The regressed upper ocean temperature anomalies in Figure 5 and the decadal variability of upper ocean heat content in Figure 4 share the same PC time series in Figure 4. 
Table 1. R-Squared Values and Their $95 \%$ Confidence Interval of Regression Between Temperature Anomalies at the Indicated Vertical Levels and the Second CSEOF Mode of the Upper Ocean Heat Content in the East/Japan Sea ${ }^{\mathrm{a}}$

\begin{tabular}{lc}
\hline Depth $(\mathrm{m})$ & R-Squared Values and $95 \%$ Confidence Interval \\
\hline 0 & $0.930(0.012)$ \\
10 & $0.928(0.013)$ \\
20 & $0.949(0.009)$ \\
30 & $0.971(0.005)$ \\
50 & $0.992(0.001)$ \\
75 & $0.991(0.002)$ \\
100 & $0.989(0.002)$ \\
125 & $0.987(0.002)$ \\
150 & $0.982(0.003)$ \\
200 & $0.973(0.005)$ \\
300 & $0.958(0.008)$ \\
\hline
\end{tabular}

${ }^{\mathrm{a}}$ The CSEOF mode is the decadal variability.

Thus, Figure 5 shows how the temperature variability in each vertical level contributes to the decadal variability of the upper ocean heat content in the EJS. The R-squared value of regression, which is the square of the correlation between the target time series and its regression in terms of predictor time series, and its 95\% confidence interval are presented in Table 1 for each vertical level. All of the levels have $\mathrm{R}$-squared values higher than 0.9 , indicating that the amplitude time series of the spatial patterns in Figure 5 are essentially identical with that of the decadal variability in Figure 4.
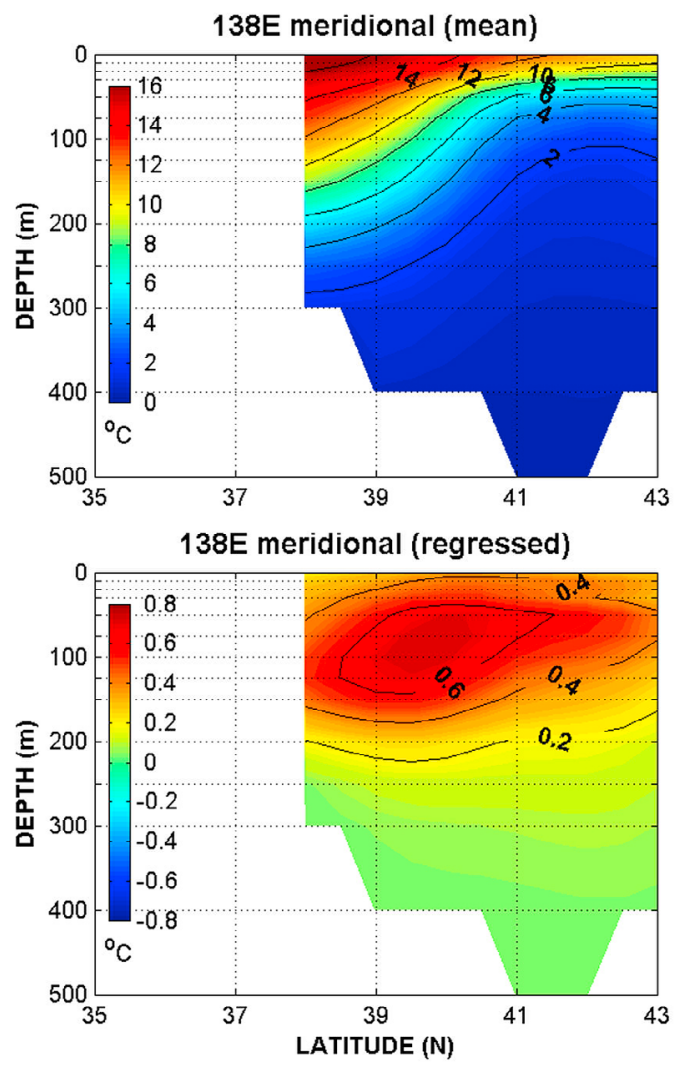

[24] The spatial patterns in Figure 5 show positive temperature anomalies over most of the domain down to approximately $125 \mathrm{~m}$; below this depth, relatively small negative temperature anomalies are observed in the southwestern and the central EJS. The positive anomalies in the upper $125 \mathrm{~m}$ are relatively large to the west of northern Honshu, at the western end of the Tsugaru Strait, and west of southern Hokkaido, where decadal heat content variability is also large (Figure 4). The temperature variations over these areas contribute significantly to the decadal variability of heat content.

[25] Vertically, the positive anomalies in the 0-30 $\mathrm{m}$ depth interval are smaller than those in the 50-125 m depth interval. The positive temperature anomalies are more uniformly spread in the $0-30 \mathrm{~m}$ depth interval, while they are more confined to the eastern part of the EJS in the 50-125 $\mathrm{m}$ depth interval (Figure 5). Larger positive temperature anomalies in the 50-125 $\mathrm{m}$ depth interval indicate that the contribution of subsurface temperature variability is greater than that of surface temperature variability to the decadal heat content variability in the EJS. This result implies that the primary source of the decadal variability is not in the surface layer but in the subsurface layer of the upper ocean and that the decadal variability is not thermally forced from the surface, at least in a one-dimensional manner. Vertical sections of the regressed temperature anomalies show more details of the decadal variability in the EJS, as described below.

[26] The $138^{\circ} \mathrm{E}$ meridional and $39^{\circ} \mathrm{N}$ zonal sections in Figure 6 are selected as central to the region of greatest
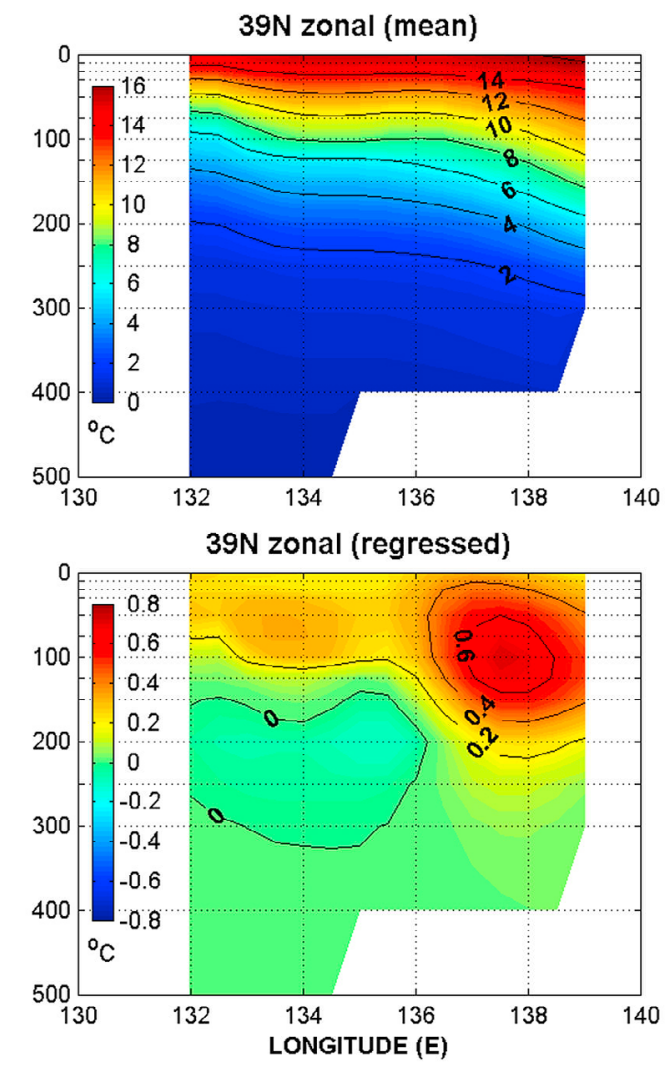

Figure 6. (top) Mean temperature and (bottom) upper ocean temperature anomalies regressed onto the decadal variability of the upper ocean heat content. (left) The $138^{\circ} \mathrm{E}$ meridional section and (right) the $39^{\circ} \mathrm{N}$ zonal section, respectively. Each spatial pattern of the temperature anomalies (Figure 6, bottom) represents the 12 month average of the loading vectors. 

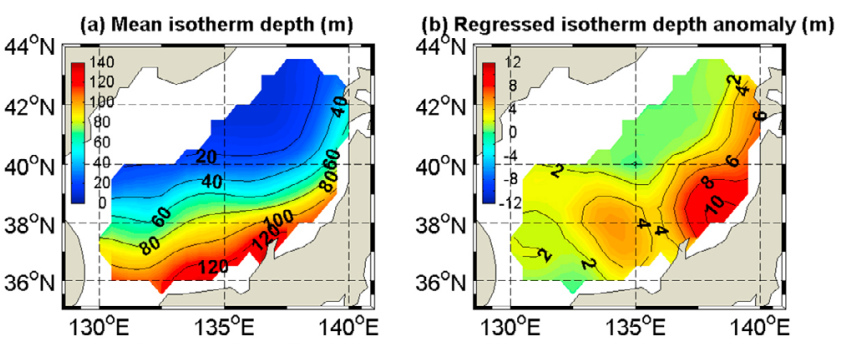

(c) Isotherm depth $(\mathrm{m})$ in 1985

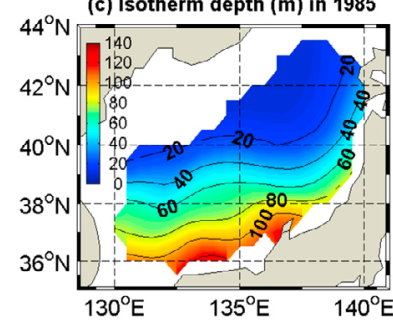$$
\text { (d) }
$$

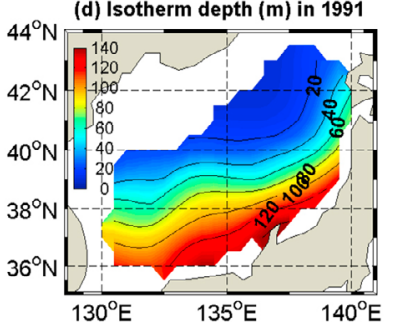

Figure 7. (a) Mean $10^{\circ} \mathrm{C}$ isotherm depth and (b) 12 month average of the $10^{\circ} \mathrm{C}$ isotherm depth anomalies regressed onto the decadal variability of the upper ocean heat content in the East/Japan Sea. The $10^{\circ} \mathrm{C}$ isotherm depths in years with (c) negative and (d) positive maximum upper ocean heat content anomalies are presented.

decadal heat content variability (Figure 4). The meridional and zonal sections in Figure 6 show the mean temperature from 1968 to 2007 . The mean temperature of the $138^{\circ} \mathrm{E}$ meridional section shows a relatively deeper thermocline south of approximately $40^{\circ} \mathrm{N}$, which is close to the Subpolar Front [Park et al., 2007]. The temperature anomalies of the $138^{\circ} \mathrm{E}$ meridional section associated with the decadal variability show large positive anomalies in the upper approximately $250 \mathrm{~m}$ of depth. The core of the temperature anomalies is centered at approximately $100 \mathrm{~m}$ and slightly to the south of $40^{\circ} \mathrm{N}$, and becomes shallower north of $40^{\circ} \mathrm{N}$. The thermocline deepens to the east, as shown in the zonal section along $39^{\circ} \mathrm{N}$ in Figure 6. The regressed temperature anomalies show large positive anomalies to the east of $136^{\circ} \mathrm{E}$. From west to east, positive temperature anomalies are observed at successively deeper levels, with a distinct core at approximately $100 \mathrm{~m}$.

[27] The spatial patterns of the regressed temperature anomalies in Figures 5 and 6 suggest that the temperature anomalies associated with decadal upper ocean heat content variability in the EJS are related to the upper ocean circulation in the EJS. Due to the lack of long-term observational surface and subsurface current data sets in the EJS, however, the depths of $10^{\circ} \mathrm{C}$ isotherms are analyzed to identify any differences in the upper ocean circulation related to the decadal upper ocean heat content variability; the depths of $10^{\circ} \mathrm{C}$ isotherms are often used to represent the upper ocean circulation in the EJS [Gordon et al., 2002]. Figure 7a shows the mean depths of $10^{\circ} \mathrm{C}$ isotherms from 1968 to 2007 , calculated from the monthly mean gridded temperature data set described in section 2.1. The mean depth of $10^{\circ} \mathrm{C}$ isotherms is greater in the southeastern EJS than in the northwestern EJS, a finding that is similar to the mean upper ocean heat content results in Figure 2a.
[28] The $10^{\circ} \mathrm{C}$ isotherm depth anomaly pattern regressed onto the decadal variability of the upper ocean heat content in the EJS shows large positive anomalies in the eastern EJS (Figure 7b). The spatial pattern in Figure $7 \mathrm{~b}$ is similar to the patterns in Figures 4 and 5. The R-squared value is approximately 0.99 , indicating that the amplitude time series of the spatial patterns in Figure $7 \mathrm{~b}$ is essentially identical with that of the decadal variability in Figure 4. Thus, the depth of the $10^{\circ} \mathrm{C}$ isotherms gets deeper when the upper ocean heat content increases, and vice versa, according to the $\mathrm{PC}$ time series in Figure 4. The $10^{\circ} \mathrm{C}$ isotherm depths in years of negative and positive maximum heat content anomalies are presented in Figures 7c and 7d, respectively. The difference between years of negative and positive anomalies becomes larger in the eastern EJS, where the spatial temperature gradient is large. Considering that the depths of the $10^{\circ} \mathrm{C}$ isotherms are often used to infer the upper ocean circulation in the EJS, particularly for the Tsushima Warm Current [Gordon et al., 2002], the variability of the Tsushima Warm Current as reflected in the variability of the $10^{\circ} \mathrm{C}$ isotherm depths appears to be related to the decadal upper ocean heat content variability in the EJS. The connection between them is discussed in section 6 .

\section{Comparison of Decadal Variability in the East/ Japan Sea With Northwestern Pacific Variability}

[29] Upper ocean circulation in the EJS, particularly the warm inflow through the Korea Strait, could be strongly associated with northwestern Pacific variability. In this section, the decadal upper ocean heat content variability in the EJS is compared with the northwestern Pacific variability and is investigated in the context of the northwestern Pacific variability. The upper ocean heat content in the northwestern Pacific was calculated from the SODA data set in the same way as that of the EJS. The decadal variability in the northwestern Pacific, which is related to the decadal variability in the EJS, was extracted as the third CSEOF mode (Figures 8a and 8c).

[30] Figure 8a shows the annually averaged spatial pattern of the decadal variability extracted from the upper ocean heat content in the northwestern Pacific using the SODA data set. The PC time series in Figure 8c shows an increasing trend from 1968 to 2007. According to the PC time series, the regions with positive anomalies experienced warming and those with negative anomalies experienced cooling during the 40 years. Positive heat content anomalies are observed over a large fraction of the northwestern Pacific, including the EJS. Negative heat content anomalies are observed to the north of the Kuroshio Extension; it appears that warming is confined to the south of the Kuroshio Extension in the northwestern Pacific.

[31] The upper ocean heat content in the northwestern Pacific was regressed onto the decadal variability of the upper ocean heat content in the EJS, and the resulting spatial pattern is shown in Figure 8b. The R-squared value of the regression is approximately 0.87 , indicating that the decadal variability in the EJS is significantly correlated with the heat content variability in the northwestern Pacific. The spatial pattern in the EJS in Figure 8b, derived from the SODA data set, is fairly similar to the spatial patterns in Figure 4, based 
(a) Decadal variability of the heat content in the NWP (b) Regressed heat content anomalies in the NWP
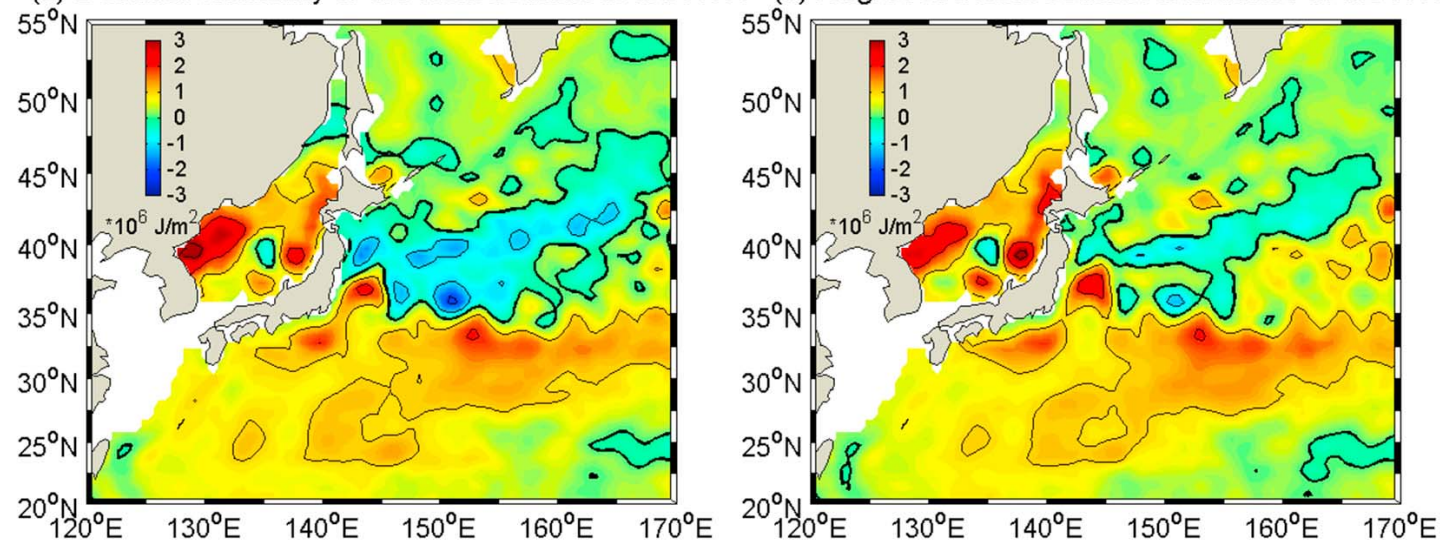

(c) PC time series of the decadal variability of the heat content in the NWP

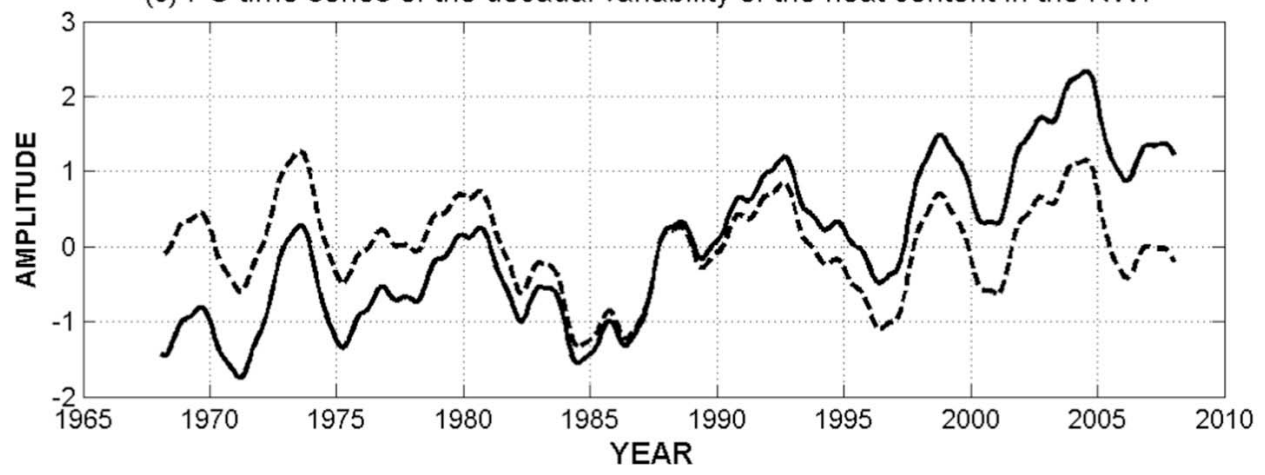

Figure 8. (a) Decadal variability of the warming signal from the upper ocean heat content in the northwestern Pacific and (c) its corresponding PC time series, and (b) a regression of the heat content in the northwestern Pacific onto the decadal variability of the upper ocean heat content in the East/Japan Sea. Each spatial pattern in Figures $8 \mathrm{a}$ and $8 \mathrm{~b}$ represents the 12 month average of the loading vectors. The bold solid lines in Figures $8 \mathrm{a}$ and $8 \mathrm{~b}$ represent the zero contours. The dotted line in Figure 8c represents the detrended PC time series.

on the observed temperature and salinity in the EJS. In particular, large positive anomalies are observed in the eastern part of the EJS along the west coast of Japan, consistent with the observational data. Large positive anomalies are also observed in the northwestern sector of the EJS in Figure $8 \mathrm{~b}$, which the observational data does not cover adequately. While ocean assimilation models in general are regarded as inaccurate for studying the marginal seas, the regressed pattern of heat content in the EJS is similar to that derived from the observational data.

[32] A comparison between Figures $8 \mathrm{a}$ and $8 \mathrm{~b}$ readily shows that the decadal variabilities of the upper ocean heat content in the EJS and in the northwestern Pacific are significantly correlated; the pattern correlation between the two is 0.91 . That is, the decadal variability in the northwestern Pacific explains a significant fraction of the decadal variability in the EJS; in fact, the two time series in Figures 4 and $8 \mathrm{~b}$ are correlated with a correlation coefficient of 0.83 . The correlation coefficient between the detrended PC time series in Figure 4 and Figure $8 \mathrm{c}$ is 0.69 . Thus, it can be inferred that the decadal variability, including the warming signal in the EJS, is a local manifestation of decadal variability and widespread warming in the northwestern Pacific, particularly to the south of approximately $35^{\circ} \mathrm{N}$. It appears that the decadal variability of the warming signal in the northwestern Pacific undergoes further modification in the EJS on decadal time scales.

\section{Discussion and Conclusions}

[33] The regression results in Figures 5, 6, and 7 suggest that the decadal variability of the upper ocean heat content in the EJS is related to the upper ocean circulation, particularly the Tsushima Warm Current variability. Considering that the maximum sill depth in the EJS is approximately $200 \mathrm{~m}$ and that the variability of the upper $200 \mathrm{~m}$ temperature is mainly governed by the Tsushima Warm Current [Chang et al., 2004; Talley et al., 2006], the depth of the maximum regressed temperature anomalies $(50-125 \mathrm{~m})$ suggests a connection between the decadal upper ocean heat content variability and the Tsushima Warm Current variability.

[34] However, the spatial patterns of positive heat content and temperature anomalies are not quite continuous along the western coast of Japan; rather, they are localized in the eastern part of the EJS, as shown in Figures 4 and 5. The localized patterns in the decadal variability of the upper ocean heat content imply complex causal dynamics. The net effect of the Tsushima Warm Current variability on the upper ocean heat content of the EJS could be altered by a number of additional factors: outflow conditions in the Tsugaru Strait 
and the Soya Strait, surface circulation and hydrography in the EJS, and the inflow conditions in the Korea Strait. With the available hydrographic data sets, it is difficult to describe in detail the dynamic linkage between the decadal variability of the Tsushima Warm Current and the upper ocean heat content. A detailed dynamic and physical explanation of the resulting patterns of heat content is beyond the scope of this study and should be postponed until accurate long-term data sets of surface and subsurface currents become available.

[35] The decadal upper ocean heat content variability in the EJS investigated in this study is generally consistent with the first decadal mode reported by Minobe et al. [2004] for the period 1957-1996. They presented a relationship between the detrended upper ocean temperature data in the EJS and the wintertime Siberian high on decadal time scales, concluding that a strong Siberian high induces a severe East Asian Winter Monsoon, which involves strong outbreaks from the Siberian coast and cold ocean temperature anomalies in the EJS. This relationship is validated for the extended time period in this study. The wintertime PC time series in Figure 4 and the low-pass filtered (half-power period of approximately 10 years) wintertime sea level pressure averaged over northern Eurasia $\left(50^{\circ}-70^{\circ} \mathrm{N}, 50^{\circ}-140^{\circ} \mathrm{E}\right)$ generally show a good agreement during the period of 1968-2007 (data not shown). This agreement implies that the decadal variability of the upper ocean heat content in the EJS and northwestern Pacific could be related to the decadal variability of the Siberian high, and possibly share the same origin.

[36] A temperature increase in the upper $1000 \mathrm{~m}$ in the EJS was reported by Kim et al. [2001, 2004], with the suggestion that the warming was associated with changes in the deepwater vertical temperature structure resulting from changes in bottom water formation. The upper $300 \mathrm{~m}$ decadal variability and increasing trend in upper ocean heat content investigated in this study does not appear to derive from such physical processes within the EJS, as shown by the similarities between the decadal variability in the EJS and that in the northwestern Pacific. Along with changes of heat content in the northwestern Pacific, the Tsushima Warm Current variability appears to be responsible for the decadal variability and increasing trend in upper ocean heat content in the EJS. Thus, the warming in the EJS is not a locally isolated and unique signal but is a local manifestation of widespread warming in the subtropical northwestern Pacific.

[37] Acknowledgments. This work was supported by grants from the Ministry of Land, Transport, and Maritime Affairs, Korea (Ocean Climate Variability Program and EAST-I Project)

\section{References}

Boyer, T. P., H. E. Garcia, D. R. Johnson, R. A. Locarnini, A. V. Mishonov, M. T. Pitcher, O. K. Baranova, and I. V. Smolyar (2006), World Ocean Database 2005, NOAA Atlas NESDIS, vol. 60, edited by S. Levitus, 192 pp., NOAA, Silver Spring, Md.

Carton, J. A., and B. S. Giese (2008), A reanalysis of ocean climate using Simple Ocean Data Assimilation (SODA), Mon. Weather Rev., 136, 2999-3017, doi:10.1175/2007MWR1978.1.

Chang, K.-I., W. J. Teague, S. J. Lyu, H. T. Perkins, D.-K. Lee, D. R. Watts, Y.-B. Kim, D. A. Mitchell, C. M. Lee, and K. Kim (2004), Circulation and currents in the southwestern East/Japan Sea: Overview and review, Prog. Oceanogr., 61, 105-156, doi:10.1016/j.pocean.2004.06.005.

Cho, Y.-K., G.-H. Seo, B.-J. Choi, S. Kim, Y.-G. Kim, Y.-H. Youn, and E. P. Dever (2009), Connectivity among straits of the northwest Pacific marginal seas, J. Geophys. Res., 114, C06018, doi:10.1029/2008JC005218.
Domingues, C. M., J. A. Church, N. J. White, P. J. Gleckler, S. E. Wijffels, P. M. Barker, and J. R. Dunn (2008), Improved estimates of upper-ocean warming and multi-decadal sea-level rise, Nature, 453, 1090-1093, doi: 10.1038 /nature 07080 .

Gordon, A. L., and C. F. Giulivi (2004), Pacific decadal oscillation and sea level in the Japan/East sea, Deep Sea Res., Part I, 51, 653-663, doi:10.1016/j.dsr.2004.02.005.

Gordon, A. L., C. F. Guilivi, C. M. Lee, H. H. Furey, A. Bower, and L. Talley (2002), Japan/East Sea intrathermocline eddies, J. Phys. Oceanogr., 32, 1960-1974, doi:10.1175/1520-0485(2002)032<1960:JESIE >2.0.CO;2.

Gouretski, V., and K. P. Koltermann (2007), How much is the ocean really warming?, Geophys. Res. Lett., 34, L01610, doi:10.1029/2006GL027834.

Han, I. S., and Y.-Q. Kang (2003), Supply of heat by Tsushima warm current in the East Sea (Japan Sea), J. Oceanogr., 59, 317-323, doi:10.1023/ A:1025563810201.

Hirose, N., C.-H. Kim, and J.-H. Yoon (1996), Heat budget in the Japan Sea, J. Oceanogr., 52, 553-574, doi:10.1007/BF02238321.

Houghton, J. T., et al. (Eds.) (1996), Intergovernmental Program on Climate Change, Climate Change 1995: The Science of Climate Change, the Contribution of Working Group 1 to the Second Assessment Report of the Intergovernmental Panel on Climate Change, 572 pp., Cambridge Univ. Press, New York.

Isoda, Y. (1999), Cooling-induced current in the upper ocean of the Japan Sea, J. Oceanogr., 55, 585-596, doi:10.1023/A:1007888718225.

Kang, Y. J., Y. Noh, and S.-W. Yeh (2010), Processes that influence the mixed layer deepening during winter in the North Pacific, J. Geophys. Res., 115, C12004, doi:10.1029/2009JC005833.

Kim, K.-Y., and G. R. North (1997), EOFs of harmonizable cyclostationary processes, J. Atmos. Sci., 54, 2416-2427, doi:10.1175/1520-0469(1997)054< 2416: $\mathrm{EOHCP}>2.0 . \mathrm{CO} ; 2$

Kim, K.-Y., G. R. North, and J. Huang (1996), EOFs of one-dimensional cyclostationary time series: Computations, examples and stochastic modeling, J. Atmos. Sci., 53, 1007-1017, doi:10.1175/1520-0469(1996)053< 1007:EOODCT>2.0.CO;2.

Kim, K., K. Kim, D. Min, Y. Volkov, J. Yoon, and M. Takematsu (2001), Warming and structural changes in the East (Japan) Sea: A clue to future changes in global oceans?, Geophys. Res. Lett., 28, 3293-3296, doi:10.1029/2001GL013078.

Kim, K., K.-R. Kim, Y.-G. Kim, Y.-K. Cho, D.-J. Kang, M. Takematsu, and Y. Volkov (2004), Water masses and decadal variability in the East Sea (Sea of Japan), Prog. Oceanogr., 61, 157-174, doi:10.1016/j.pocean. 2004.06.003.

Levitus, S., J. Antonov, T. Boyer, and C. Stephens (2000), Warming of the world ocean, Science, 287, 2225-2229, doi:10.1126/science.287.5461.2225.

Levitus, S., J. Antonov, and T. Boyer (2005), Warming of the world ocean, 1955-2003, Geophys. Res. Lett., 32, L02604, doi:10.1029/2004GL021592.

Levitus, S., J. I. Antonov, T. P. Boyer, R. A. Locarnini, H. E. Garcia, and A. V. Mishonov (2009), Global ocean heat content 1955-2008 in light of recently revealed instrumentation problems, Geophys. Res. Lett., 36 , L07608, doi:10.1029/2008GL037155.

Lozier, M. S., S. Leadbetter, R. G. Williams, V. Roussenov, M. S. C. Reed, and N. J. Moore (2008), The spatial pattern and mechanisms of heatcontent change in the North Atlantic, Science, 319, 800-803, doi:10.1126/ science. 1146436 .

Lyman, J. M., S. A. Good, V. V. Gouretski, M. Ishii, G. C. Johnson, M. D. Palmer, D. M. Smith, and J. K. Willis (2010), Robust warming of the global upper ocean, Nature, 465, 334-337, doi:10.1038/nature09043.

Minobe, S., A. Sako, and M. Nakamura (2004), Interannual to interdecadal variability in the Japan Sea based on a new gridded upper water temperature dataset, J. Phys. Oceanogr., 34, 2382-2397, doi:10.1175/JPO2627.1.

Na, H., Y. Isoda, K. Kim, Y. H. Kim, and S. J. Lyu (2009), Recent observations in the straits of the East/Japan Sea: A review of hydrography, currents and volume transports, J. Mar. Syst., 78, 200-205, doi:10.1016/j. jmarsys.2009.02.018.

Na, H., K.-Y. Kim, K.-I. Chang, K. Kim, J.-Y. Yun, and S. Minobe (2010), Interannual variability of the Korea Strait bottom cold water and its relationship with the upper water temperatures and atmospheric forcing in the Sea of Japan (East Sea), J. Geophys. Res., 115, C09031, doi:10.1029/ 2010JC006347.

Palmer, M. D., S. A. Good, K. Haines, N. A. Rayner, and P. A. Stott (2009), A new perspective on warming of the global oceans, Geophys. Res. Lett., 36, L20709, doi:10.1029/2009GL039491.

Park, J. J., and K. Kim (2007), Evaluation of calibrated salinity from profiling floats with high resolution conductivity-temperature-depth data in the East/Japan Sea, J. Geophys. Res., 112, C05049, doi:10.1029/2006JC003869.

Park, K.-A., D. S. Ullman, K. Kim, J. Y. Chung, and K.-R. Kim (2007), Spatial and temporal variability of satellite-observed Subpolar Front in the East/Japan Sea, Deep Sea Res., Part I, 54, 453-470, doi:10.1016/j. dsr.2006.12.010. 
Takikawa, T., J.-H. Yoon, and K.-D. Cho (2005), The Tsushima warm current through Tsushima Straits estimated from ferryboat ADCP data, J. Phys. Oceanogr., 35, 1154-1168, doi:10.1175/JPO2742.1.

Talley, L. D., D.-H. Min, V. B. Lobanov, V. A. Luchin, V. I. Pnomarev, A. N. Salyuk, A. Shcherbina, P. Y. Tishchenko, and I. Zhabin (2006), Japan/East Sea water masses and their relation to the sea's circulation, Oceanography, 19, 32-49, doi:10.5670/oceanog.2006.42.

Willis, J. K., D. Roemmich, and B. Cornuelle (2004), Interannual variability in upper ocean heat content, temperature, and thermosteric expansion on global scales, J. Geophys. Res., 109, C12036, doi:10.1029/2003JC002260.

Yoon, J.-H., and Y.-J. Kim (2009), Review on the seasonal variation of the surface circulation in the Japan/East Sea, J. Mar. Syst., 78, 226-236, doi:10.1016/j.jmarsys.2009.03.003.
Zheng, Y., and B. S. Giese (2009), Ocean heat transport in Simple Ocean Data Assimilation: Structure and mechanisms, J. Geophys. Res., 114, C11009, doi:10.1029/2008JC005190.

K.-I. Chang, K.-Y. Kim, and H. Na, School of Earth and Environmental Sciences, Seoul National University, 599 Gwanak-ro, Gwanak-gu, Seoul 151-742, South Korea. (kwang56@snu.ac.kr)

K. Kim, Research Institute of Oceanography, Seoul National University, Seoul 151-742, South Korea.

S. Minobe, Graduate School of Science, Hokkaido University, Sapporo, Hokkaido 060-0810, Japan.

J. J. Park, Department of Physical Oceanography, Woods Hole Oceanographic Institution, Woods Hole, MA 02543, USA 